\title{
Diagnostic role of fine needle aspiration cytology (FNAC) in the evaluation of salivary gland swelling: an institutional experience
}

\author{
Samreen Naz ${ }^{1}$, Atif Ali Hashmi ${ }^{1}$, Amna khurshid ${ }^{1}$, Naveen Faridi ${ }^{1}$, Muhammad Muzzammil Edhi ${ }^{2}$,
} Anwar Kamal ${ }^{1}$ and Mehmood Khan ${ }^{3 *}$

\begin{abstract}
Background: Fine needle aspiration cytology (FNAC) is a cytodiagnostic method based on morphologic findings of individual and small group of cells aspirated using a fine needle. The aim of the present study is to evaluate the spectrum of salivary gland lesions in our setting and to assess the diagnostic accuracy of FNAC for salivary gland lesions.

Methods: The study involved 187 cases of parotid and submandibular swellings of patients who underwent FNAC at our institution. Thirty one (31) patients with a FNAC diagnosis of neoplastic lesion subsequently underwent excision biopsies. The results of FNAC and final histology were compared and accuracy of FNAC was determined.

Results: Mean age of patients was $42( \pm 21)$ years and male to female ratio was 1:1. Chronic sialadenitis was the most common non-neoplastic lesion (33.8\%) followed by acute and chronic sialadenitis (29.7\%) and chronic granulomatous inflammation (27.0\%). Pleomorphic adenoma was the most common benign neoplasm and non-Hodgkin's lymphoma was the most common malignant lesion (38.9\%) followed by acinic cell (27.8\%) and adenoid cystic carcinoma (16.7\%). Total 31 patients subsequently underwent surgical excision, out of which 21 were benign and 9 were malignant, 20 cases (64.5\%) were of pleomorphic adenoma, 3 cases (9.6\%) of acinic cell carcinoma, 2 cases (6.4\%) each of warthin tumor, adenoid cystic carcinoma and non-hodgkin lymphoma and 1 case (3.2\%) each of mucoepidermoid carcinoma and mucinous adenocarcinoma. The overall accuracy of FNAC in our study was found to be $83.8 \%$ with $77.7 \%$ sensitivity and $86.3 \%$, specificity. The revised sensitivity and specificity after adjusting verification bias were $68.5 \%$ and $91 \%$ respectively. False negative diagnosis was rendered in mucoepidermoid carcinoma and acinic cell carcinoma whereas false positive diagnosis was given in cases of pleomorphic adenoma.
\end{abstract}

Conclusion: We found a good concordance between FNAC and histology, however pleomorphic adenoma may impart a diagnostic challenge when inadequately aspirated and therefore we advice either immunohistochemical studies (if cell block material is available) or repeat aspiration in difficult cases.

Keywords: Salivary gland, Fine needle aspiration (FNAC), Parotid gland, Submandibular gland

\section{Background}

Fine needle aspiration cytology (FNAC) is a cytodiagnostic method based on morphologic findings of individual and small group of cells aspirated using a fine needle. FNAC was introduced in 1920's and soon it gained wide acceptance among clinicians due to ease of its performance and rapidity of diagnosis [1]. Nowadays

\footnotetext{
* Correspondence: mehmoodkhan955@yahoo.com

${ }^{3}$ Dhaka Medical College, Dhaka, Bangladesh

Full list of author information is available at the end of the article
}

FNAC has become a cornerstone diagnostic tool in head and neck swellings $[2,3]$.

The role of FNAC in suspected salivary gland swellings is two folds. Firstly to confirm the origin as preauricular and submandibular lymph node swellings can mimic salivary gland neoplasm clinically and secondly to get a preliminary diagnosis about the nature of the disease process before embarking on definite management plan. FNAC is a reliable method to differentiate between inflammatory and neoplastic lesions. FNAC diagnosis of neoplastic process even when benign usually lead to 
Table 1 Cytologic diagnostic categories

\begin{tabular}{lll}
\hline Cytologic diagnostic category & Frequency (n) & Percentage (\%) \\
\hline Non-diagnostic & 8 & $4.3 \%$ \\
Inflammatory/non-neoplastic & 74 & $39.6 \%$ \\
Benign neoplasm & 64 & $34.2 \%$ \\
Suspicious for malignancy & 23 & $12.2 \%$ \\
Malignant & 18 & $9.6 \%$
\end{tabular}

surgical excision. Although diagnostic accuracy of FNAC in the assessment of salivary gland swellings has been studied in various studies, it has not been widely assessed in our set up [4-7]. The aim of the present study is to evaluate the spectrum of salivary gland lesions in our setting and to assess the diagnostic accuracy of FNAC for salivary gland lesions.

\section{Methods}

This is a retrospective observational study performed in the department of histopathology, Liaquat National Hospital for duration of four (4) years. The study involved 187 cases who presented with parotid and submandibular swellings. The study was approved by Liaquat National hospital and medical college research and ethical review committee. FNAC was performed using a $22-23$ gauge needle attached to a disposable syringe with plunger under aseptic conditions. Smears were performed and slides were stained with haemotoxylin and eosin, Papanicolou and giemsa methods. Remaining material was processed as cell block preparation and processed according to standard guidelines. Thirty one (31) patients with a FNAC diagnosis of neoplastic lesion subsequently underwent excision biopsies. After gross examination of specimens, the representative sections were processed and examined by $\mathrm{H} \& \mathrm{E}$ methods. Special and immunohistochemical stains were performed when necessary. The results of FNAC and final histology were compared and accuracy of FNAC was determined.

\section{Statistical analysis}

The cytological and histological analysis was reported in terms of frequencies and percentages. Furthermore, diagnostic accuracy of FNAC for salivary gland swellings was measured using Histopathology as Gold Standard. Sensitivity, Specificity, NPV and PPV were calculated using formulas listed below.

Table 2 Cytologic diagnosis of non-neoplastic lesions

\begin{tabular}{lll}
\hline Cytological diagnosis & Frequency (n) & Percentage (\%) \\
\hline Chronic granulomatous inflammation & 20 & $27.0 \%$ \\
Chronic sialadenitis & 25 & $33.7 \%$ \\
Acute on chronic sialdenitis & 22 & $29.7 \%$ \\
Benign cystic lesion & 7 & $9.4 \%$ \\
Total & 74 & $39.5 \%$ \\
\hline
\end{tabular}

Table 3 Cytologic diagnosis of benign neoplasms

\begin{tabular}{lll}
\hline Cytological diagnosis & Frequency $\mathbf{( n )}$ & Percentage (\%) \\
\hline Pleomorphic adenoma & 57 & $89.0 \%$ \\
Warthin tumor & 7 & $10.9 \%$ \\
Total & 64 & $34.2 \%$ \\
\hline
\end{tabular}

$$
\begin{aligned}
\mathrm{PPV} & =\frac{\text { number of true positives }}{\text { number of true positives }+ \text { number of false positives }} \\
& =\frac{\text { number of true positives }}{\text { number positives calls }} \\
\mathrm{NPV} & =\frac{\text { number of true negatives }}{\text { number of true negatives }+ \text { number of false negatives }} \\
& =\frac{\text { number of true negatives }}{\text { number negative calls }}
\end{aligned}
$$$$
\text { accuracy }=\frac{\text { number of true positives }+ \text { number of true negatives }}{\text { number of true positives }+ \text { false positives }}
$$$$
+ \text { false negatives }+ \text { true negatives }
$$$$
\text { sensitivity }=\frac{\text { number of true positives }}{\text { number of true positives }+ \text { number of false negatives }}
$$$$
\text { specificity }=\frac{\text { number of true negatives }}{\text { number of true negatives }+ \text { number of false positives }}
$$

In addition, Sensitivity and Specificity were also adjusted for verification bias.

$$
\begin{aligned}
& \text { Sens }=(T=1 / D=1)=\frac{\frac{n_{1} s_{1}}{s_{1}+r_{1}}}{\frac{n_{1} s_{1}}{s_{1}+r_{1}}+\frac{n_{2} s_{2}}{s_{2}+r_{2}}} \\
& \text { Spe }=p(T=0 / D=0)=\frac{\frac{n_{2} s_{2}}{s_{2}+r_{2}}}{\frac{n_{1} s_{1}}{s_{1}+r_{1}}+\frac{n_{2} s_{2}}{s_{2}+r_{2}}}
\end{aligned}
$$

\section{Results}

The mean age of patients was $42( \pm 21)$ years and male to female ratio was $1: 1$. Out of 187 patients who underwent FNAC, 8 cases were non-diagnostic due to lack of adequate material, 74 were non-neoplastic/inflammatory. In 49 cases a diagnosis of neoplastic process was rendered, out of which 23 were benign and an unequivocal diagnosis of malignancy was given in $18(9.6 \%)$ cases as shown in Table 1 . Chronic sialadenitis was the most common non-neoplastic lesion (33.8\%) followed by acute

Table 4 Cytologic diagnosis of malignant neoplasms

\begin{tabular}{lll}
\hline Cytological diagnosis & Frequency $(\mathbf{n})$ & Percentage (\%) \\
\hline Mucoepidermoid carcinoma & 2 & $11.1 \%$ \\
Acinic cell carcinoma & 5 & $27.7 \%$ \\
Adenoid cystic carcinoma & 3 & $16.6 \%$ \\
Lymphoproliferative disorder & 7 & $38.8 \%$ \\
Papillary adenocarcinoma & 1 & $5.5 \%$ \\
Total & 18 & $9.6 \%$ \\
\hline
\end{tabular}


Table 5 Comparison of cytologic and histologic diagnosis

\begin{tabular}{|c|c|c|c|c|c|c|c|c|}
\hline \multirow[t]{3}{*}{ Cytologic diagnosis } & \multicolumn{8}{|c|}{ Histologic diagnosis } \\
\hline & & $\begin{array}{l}\text { Pleomorphic } \\
\text { adenoid }\end{array}$ & $\begin{array}{l}\text { Mucoepidermoid } \\
\text { carcinoma }\end{array}$ & $\begin{array}{l}\text { Mucinous } \\
\text { adenocarcinoma }\end{array}$ & $\begin{array}{l}\text { Adenoid cystic } \\
\text { carcinoma }\end{array}$ & $\begin{array}{l}\text { Nonhodgkin } \\
\text { lymphoma }\end{array}$ & $\begin{array}{l}\text { Acinic cell } \\
\text { carcinoma }\end{array}$ & $\begin{array}{l}\text { Warthin } \\
\text { tumor }\end{array}$ \\
\hline & Total & Frequency (n) & Frequency (n) & Frequency (n) & Frequency (n) & Frequency (n) & Frequency (n) & Frequency (n) \\
\hline Pleomorphic adenoma & 19 & 17 & 1 & & 1 & & & \\
\hline Warthin tumor & 2 & & & & & & & 2 \\
\hline Suspicious for malignancy & 2 & 1 & & 1 & & & & \\
\hline Mucoepidermoid carcinoma & 1 & 1 & & & & & & \\
\hline Acinic cell carcinoma & 3 & & & & & & 3 & \\
\hline Adenoid cystic carcinoma & 2 & 1 & & & 1 & & & \\
\hline $\begin{array}{l}\text { Lymphoproliferative } \\
\text { disorder }\end{array}$ & 2 & & & & & 2 & & \\
\hline
\end{tabular}

and chronic sialadenitis (29.7\%) and chronic granulomatous inflammation (27.0\%) (Table 2). Pleomorphic adenoma was the most common benign neoplasm (Table 3) and non-Hodgkin's lymphoma was the most common malignant lesion (38.9\%) followed by acinic cell $(27.8 \%)$ and adenoid cystic carcinoma (16.7\%) (Table 4).

Out of these 187 cases, 31 patients subsequently underwent surgical excision/histologic evaluation, out of which 21 were benign and 9 were malignant, Total 31 patients subsequently underwent surgical excision, out of which 21 were benign and 9 were malignant, 20 cases (64.5\%) were of pleomorphic adenoma, 3 cases $(9.6 \%)$ of acinic cell carcinoma, 2 cases (6.4\%) each of warthin tumor, adenoid cystic carcinoma and non-hodgkin lymphoma and 1 case (3.2\%) each of mucoepidermoid carcinoma and mucinous adenocarcinoma. Table 5 shows the comparison of cytologic and histologic diagnosis. Overall accuracy of FNAC in our study was found to be $83.8 \%$ with $77.7 \%$ sensitivity and $86.3 \%$, specificity as shown in Table 6 . The revised sensitivity and specificity after adjusting verification bias were 68.5\% (37.9-99.2) and 91\% (82.799.3) respectively (Table 7 ).

\section{Discussion}

Swelling of salivary glands, specifically parotid and submandibular gland presents as a common problem and being readily visible creates havoc among patients. In addition parotid/submandibular swellings also remain a

Table 6 Diagnostic accuracy of FNAC for Salivary gland swelling

\begin{tabular}{ll}
\hline Sensitivity & $77.7 \%$ \\
Specificity & $86.3 \%$ \\
Positive predictive value & $70 \%$ \\
Negative predictive value & $90.4 \%$ \\
Accuracy & $83.3 \%$ \\
\hline
\end{tabular}

diagnostic challenge among clinicians. FNAC provides a convenient way to obtain a tissue based diagnosis and therefore has now become a diagnostic test of choice to solve this dilemma. Our study explains the role of this procedure in our setup to diagnose salivary gland lesions and the spectrum of disease pathology in our population.

Literature review revealed a wide variation in the sensitivity and specificity of FNAC for salivary gland swelling in different populations and setups [8-10]. Zerpa et al. studied 93 cases of parotid gland tumors, revealing a sensitivity and specificity of $57 \%$ and $95 \%$ respectively [11]. On the other hand, Pastore et al. found a sensitivity and specificity of $83 \%$ and $93 \%$ respectively. They evaluated 357 cases of salivary gland lesions [12]. Similarly Jaein et al. revealed $92.8 \%$ sensitivity and $93.9 \%$ specificity in a study involving 80 cases of salivary gland swellings, out of which 14 cases were of malignant salivary gland neoplasms [13]. Kim et al. found a diagnostic accuracy of FNAC to be $92 \%$ in differentiating malignant from benign salivary gland tumors [14]. Fakhry et al. evaluated 249 parotid tumors, out of which $75 \%$ were benign and $25 \%$ were malignant. The sensitivity and specificity to detect malignancy was assessed to be $80 \%$ and $89.5 \%$ respectively. They found 16 false positive results, among which warthin's tumor and pleomorphic adenoma were most common, while false negative diagnosis were given in cases of lymphomas and mucoepidermoid carcinomas. The diagnostic accuracy for benign and malignant tumors was $16 \%$ and $44 \%$ respectively [15].

Table 7 Revised sensitivity and specificity after adjusting verification bias

\begin{tabular}{llll}
\hline & & \multicolumn{2}{l}{$\mathbf{9 5 \%}$ confidence interval } \\
\cline { 3 - 4 } & & Upper limit & Lower limit \\
\hline Sensitivity & $68.5 \%$ & $37.9 \%$ & $99.2 \%$ \\
Specificity & $91.0 \%$ & $82.7 \%$ & $99.3 \%$ \\
\hline
\end{tabular}


We found an overall diagnostic accuracy of FNAC to be $83.8 \%$. There were two cases of false negative diagnosis. These two cases were one each of mucoepidermoid carcinoma and acinic cell carcinoma which were initially diagnosed as pleomorphic adenoma on FNAC. Pleomorphic adenoma is a biphasic neoplasm. The epithelial component may present a variety of histologic patterns including squamous and ductal structures and they may sometimes exhibit significant cytologic atypia. Lack of stromal component in the aspirated material may lead to a false positive diagnosis especially that of low grade mucoepidermoid carcinoma which may show diversity in the morphologic patterns of epithelial components including squamous, intermediate and mucinous cells. There were 3 cases of false positive diagnosis. In one of that case there were extensive squamous elements without any other component and therefore a diagnosis of neoplastic lesion, suspicious for malignancy was given with a possibility of metastatic squamous cell carcinoma and mucoepidermoid carcinoma. The final histology revealed the diagnosis of pleomorphic adenoma. The other two cases with false negative diagnosis were that of mucoepidermoid and adenoid cystic carcinoma which were inaccurately diagnosed on FNAC as pleomorphic adenoma. Adenoid cystic carcinoma is a close differential of pleomorphic adenoma and basal cell adenoma. This differentiation is very important as the surgical management is different. Adenoid cystic carcinoma shows basement membrane like material which may be misinterpreted as stromal component. The epithelial component of adenoid cystic carcinoma is usually very bland leading to inaccurate impression of benignancy. Immunohistochemical studies on cell block material may be very helpful in this distinction including stains for basal lamina and CD117 stain which is positive in adenoid cystic carcinoma.

A few studies were also conducted in Pakistan, evaluating the role of FNAC in salivary gland pathology. A study conducted in Pakistan including 129 cases of parotid gland lesions, revealed 98 benign and 31 malignant neoplasms. Pleomorphic adenoma was the most common benign tumor while mucoepidermoid carcinoma being the most common malignant diagnosis [16]. In our study, although pleomorphic adenoma was the most common benign tumor, however the most common malignant tumor was acinic cell carcinoma.

\section{Conclusion}

In conclusion, we found a good concordance between FNAC and final histology, however pleomorphic adenoma may impart a diagnostic challenge when inadequately aspirated and therefore either immunohistochemical studies should be done if cell block material is available or repeat aspiration should be advised before embarking on therapeutic excision.
Abbreviations

FNAC: Fine needle aspiration cytology; H\& E: Hematoxylin and eosin.

\section{Competing interests}

The authors declare that they have no competing interests.

\section{Authors' contributions}

SN and AAA: main authors of manuscript, have made substantial contributions to design of data. AK: have made substantial contributions to analysis and interpretation of data. NF and MME: Involved in drafting and revision of the manuscript. AK and MK: have been involved in drafting the manuscript. All authors read and approved the final manuscript.

\section{Acknowledgments}

We gratefully acknowledge all staff members of Pathology department, Liaquat national hospital and medical college, Karachi, Pakistan for their help and cooperation.

\section{Author details}

${ }^{1}$ Department of Histopathology, Liaquat National Hospital and Medical College, Karachi, Pakistan. 'Liaquat National Hospital and Medical College, Karachi, Pakistan. ${ }^{3}$ Dhaka Medical College, Dhaka, Bangladesh.

Received: 7 September 2014 Accepted: 11 March 2015

Published online: 27 March 2015

\section{References}

1. Dudheon LS, Patrick CV. A new method for the rapid microscopical diagnosis of tumors. Br J Surg. 1927;15:250-61.

2. Rajbhandari M, Dhakal P, Shrestha S, Sharma S, Shrestha S, Pokharel M, et al. The correlation between fine needle aspiration cytology histopahology of head and neck lesion in kathmandu university hospital. Kathmandu Univ Med J (KUMJ). 2013;11(44):296-9.

3. Poorey VK, Tyagi A. Accuracy of fine needle aspiation cytology in head and neck masses. Indian J Otolaryngol Head Neck Surg. 2014;66(2):182-6.

4. Diaz KP, Gerhard R, Domingues RB, Martins LL, Prado Ribeiro AC, Lopes MA, et al. High diagnistic accuracy and reproducibility of fine needle aspiration cytology for diagnosing salivary gland tumors : cytohistologic correlation in 182 cases. Oral Surg Oral Med Oral Pathol Oral Radiol. 2014;118(2):226-35.

5. Huq AH, Aktaruzzaman M, Habib MA, Islam MS, Amin S. A comperative study between fine needle aspiration cytology findings and histopathological report of major salivary gland neoplasm in a tertiary hospital of bangladesh. Bangladesh Med Res Counc Bull. 2013;39(2):69-73.

6. Kechagias N, Ntomouchtsis A, Valeri R, Patrikidou A, Kitikidou K, Xirou P, et al. Fine needle aspiration cytology of salivary gland tumors: a 10 years retrospective analysis.". Oral Maxilofac Surg. 2012;16(1):35-40.

7. Singh Nanda KD, Meht A, Nanda J. Fine needle aspiration cytology : a reliable tool in the diagnosis of salivary gland lesions. J Oral Pathol Med. 2012;41(1):106-12.

8. Murai N, Taniguchi Z, Takahashi Y, Kuboshima F, Tateya I. A study of salivary gland aspiration cytology reporting: guideline validity. Nihon Jibiinkoka Gakkai Kaiho. 2011;114(7):615-9.

9. Piccioni LO, Fabiano B, Gemma M, Sarandria D, Bussi M. Fine needle aspiration cytology in the diagnosis of parotid lesions. Acta Otorhinolaryngol Ital. 2011;31(1):1-4.

10. Singh A, Haritwal A, Murali B. Correlation between cytology and histopathology of th salivary gland. Australas Med J. 2011;4(2):66-71.

11. Zerpa Zerpa V, Cuesta Gonzales MT, Agostini Porras G, Marcano Acuna M, EstellesFerriol E, Dalmau GJ. Diagnostic accuracy of fine needle aspiration cytology in parotid tumors. Acta Otorrinolaringol Esp. 2014;65(3):157-61.

12. Pastore A, Borin M, Malagutti N, Di Laora A, Becati D, Delazer AL, et al. Preopertive assisment of salivary gland neoplasm with fine needle aspiration cytology and echography: a retrospective analysis of 357 cases. Int J Immunopathol Pharmacol. 2013;26(4):965-71.

13. Jain R, Gupta R, Kudesia M, Sing S. Fine needle aspiration cytology in the diagnosis of salivary gland lesions: a study with histologic comparison. Cytojournal. 2013;10:5.

14. Kim BY, Hyeon J, Ryu G, Choi N, Baek CH, Ko YH, et al. Diagnostic accuracy of fine needle aspiration cytology for high grade salivary gland tumors. Ann Surg Oncol. 2013;20(7):2380-7. 
15. Fakhry N, Antonini F, Michel J, Penicaud M, Mancini J, Lagier A, et al. Fine needle aspiration cytology in the management of parotid masses: evaluation of 249 patient. Eur Ann Otorhinolaryngol Head Neck Dis. 2012:129(3):131-5

16. Ali NS, Akhtar S, Junaid M, Awan S, Aftab K. Diagnostic accuracy of fine needle aspiration cytology in parotid lesions. ISRN Surg. 2011;2011:721525.

Submit your next manuscript to BioMed Central and take full advantage of:

- Convenient online submission

- Thorough peer review

- No space constraints or color figure charges

- Immediate publication on acceptance

- Inclusion in PubMed, CAS, Scopus and Google Scholar

- Research which is freely available for redistribution 